\title{
Barriers in use of colostrum, Breast milk, and supplemental feed: assessing maternal Knowledge \& practices
}

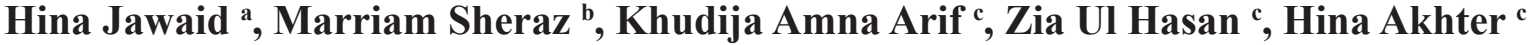 \\ ${ }^{a}$ Assistant Professor Department of Family Medicine, University of Health Sciences, Lahore. \\ ${ }^{b}$ Medical Officer, Department of Family Medicine, FMH College of Medicine \& Dentistry, Shadman, Lahore. \\ 'Senior Registrar Department of Family Medicine, FMH College of Medicine \& Dentistry, Shadman, Lahore. \\ *Corresponding Author: drmarriamkhalid@gmail.com
}

\section{ABSTRACT}

BACKGROUND \& OBJECTIVE: Colostrum and breast milk are not only highly nutritious but also a source of maternal antibodies for infants. We explore maternal awareness and barriers in use of colostrum and breast milk.

METHODOLOGY: This cross-sectional study included mothers of children aged 3 years or less who visited primary care centers in urban and peri-urban areas of Lahore, Pakistan, between December 2020 to March 2021.

RESULTS: A total of 384 mothers were included in the study, mean age was 28 years. $47 \%(\mathrm{n}=179)$ had primary or secondary school education. Higher maternal education $(\mathrm{p}=0.05)$ and age were associated with better knowledge about the benefits of colostrum. Reasons for not giving colostrum among mothers without formal education (42\%) were "it's not clean milk", while $38 \%$ of mothers with higher education give a reason they could not feed because find it difficult due to $\mathrm{C}$-section. Use of supplemental feed was noted across all educational levels, $60 \%$ mothers with no educational background preferred bovine milk, whereas $79 \%$ of highly qualified ones preferred formula milk $(\mathrm{p}=0.00)$. The use of formula milk was more frequently observed in families with 100,000 PKR per month and above $(\mathrm{p}=0.00) .80 \%$ of mothers were unaware that bovine milk in infants can lead to anemia.

CONCLUSION: There is inadequate knowledge, among mothers of all educational levels with reference to colostrum use and the relationship between consumption of bovine milk by infants and iron deficiency. Measures to improving maternal nutritional awareness and optimize infant feeding practices during antenatal visits are needed.

KEYWORDS: Colostrum, Breast Milk, Maternal knowledge, Use of Supplemental Feed, Anemia.

\section{INTRODUCTION}

Colostrum is the first secretion from the mammary gland, which start expressing in the third trimester ${ }^{[1,2]}$. It is yellowish-white or bluish white milk rich in proteins and IgA immunoglobulin and is crucial for the development of infants ${ }^{[3]}$. There are myths and misconceptions related to its use, which leads to a barrier in its consumption ${ }^{[4]}$. In some cultures, women discard the colostrum because they have a misconception that this is an unhealthy part of breast milk and the cause of morbidity in child ${ }^{[4]}$. Studies have shown that the negative attitude about colostrum fe+eding contributed more to its lack of use rather than the paucity of maternal knowledge. Those who regularly attend antenatal visits and receive counseling regarding the use of first milk another study concluded that a significant proportion of mothers had negligible awareness and misunderstanding that colostrum is not milk, not nutritious, and cause diarrhea. This practice is more prevalent in mothers without formal education, new mothers, and those who had home deliveries ${ }^{[4]}$. In addition to avoiding feeding colostrum to their babies, pre-lacteal feeding is exercised in a significant proportion of mother ${ }^{[5]}$. Breast milk contains Human Milk Oligosaccharides (HMOs), which are important for the development of immune system of infants gut flora and for brain development ${ }^{[6]}$. Studies have proven that children who were exclusively breastfeed for more than six months have higher IQ level ${ }^{[7]}$. Myelination is the backbone of neurodevelopment, and breast milk contains docosahexaenoic and arachidonic acid that contains more than $20 \%$ of brain fatty acid content and phospholipids that make $10 \%$ lipid weight of myelin, about $40 \%$ of the lipid content of breast milk is sphingomyelin which is crucial for myelin sheath development so breast milk is very important

Jawaid H, Sheraz M, Arif KA, Hasan ZU, Akhter H. Barriers in use of colostrum, Breast milk and supplemental feed: assessing maternal Knowledge \& practices. Journal of University Medical \& Dental College. 2022; 13(1):346-350. 
for overall cognitive development of child ${ }^{[8]}$.

WHO_UNICEF reports breastfeeding standards are not completely followed by any country, only 23/194 countries have more than $60 \%$ rate of exclusive breastfeeding. In Pakistan, only $37.7 \%$ of mothers exclusively breastfeed for 6 months while only 18\% initiate it early after birth. $44 \%$ of children in Pakistan are malnourished and have developmental delay ${ }^{[9]}$. WHO committed a "comprehensive implementation plan on maternal, infant and young child nutrition" one of its targets is to increase the rate of exclusive breastfeeding to at least $50 \%$ by $2025^{[10]}$. Evidence from local studies have highlighted elements other than maternal knowledge deficit, which favour switching from breast milk to formula milk, these include mothers' excessive workload, social and cultural influence, and marketing of infant formula ${ }^{[11,12]}$. Even in places where the vast majority of caregivers, only a small percentage exclusively breast feed the child ${ }^{[13]}$. In terms of breast-feeding practices across the world at places as high as $93.2 \%$ of mothers breastfeed their child, but only $33 \%$ practice exclusive breastfeeding (EBF) for 6 months ${ }^{[14]}$. A study done in Pakistan showed that $51 \%$ of mothers give supplemental feed before six months of age [15] whereas in other places only $36 \%$ of infants receive breastfeeding within hour of birth and $50 \%$ were exclusively breast fed for six months ${ }^{[16]}$. Elders and socio-cultural influence also play a vital role on the perception of mother and thus feeding practice of infant. Accurate grandmothers' knowledge is transmitted to mother and thus facilitates the correct breast-feeding practice ${ }^{[17]}$.

Our study was designed to assess mothers understanding and knowledge, myths and misconceptions about colostrum and breastfeeding practices. This study also aims to identify the social and cultural beliefs which contributes in, not giving the colostrum and breast milk and explored the reason of giving top feed. We also explore the knowledge of mother about importance of colostrum, breastfeeding. American academy of pediatrics does not recommend use of cow milk during the first year of life ${ }^{[18]}$. Bovine milk leads to iron deficiency anemia ${ }^{[19,20]}$ maternal knowledge about it was also explored in our study.

\section{METHODOLOGY}

Ethical approval was obtained from the Institutional Review Board (IRB) of Fatima Memorial Hospital (IRB number FMH-11-2020-IRB). This study was part of a larger research project where existing feeding practices and what forms the basis of avoiding certain foods in toddlers and pre-school children were explored through survey questionnaires / interviews with mothers.

The survey was conducted between December 2020 and March 2021 among mothers of young children of up to 3 years, who were able to provide written / verbal informed consent and was willing to participate. Responses were collected through face-to-face interview, phone call and online questionnaires. Due to Covid situation, the phone call and online questionnaire were used to collect the data, other than face to face interviews. A questionnaire was designed in Urdu and English language for this purpose. Data was collected from the following primary and secondary health care centers;

1. Nainsukh primary health care centre of Fatima Memorial Hospital, Lahore.

2. Gajjumata primary health care centre part of Fatima Memorial Hospital, Lahore.

3. Fatima Memorial Hospital OPD shadman Lahore.

Two remote villages, a village of Mubarakabad and Nehranwal in central Punjab close to okara were identified, and a local person was trained to gather information.

The sample size was of 384 calculated based on the confidence interval of $95 \%$. We use Rao soft sample size calculator to calculate the sample size. Mothers who were unable to write their names were categorized as mothers without formal education, those that attended school (primary or secondary) which is or been to college were grouped as "intermediate" education (upto 12 years of education) while those who acquired university qualification (more than 12 years of education) were classed as "highly educate. We defined mothers of less than 30 years of age as young mothers and mothers more than 30 years as mature mothers.

Supplemental feed is defined as feedings provided to infants in addition to breastfeeding. Any foods given prior to 6 months of age, the recommended duration of exclusive breastfeeding [21]. Rural area is open land with less dense population, and urban area is city and area surrounding city [22]. Mothers who had one or more children of age up to 3 years were included. Children with cleft palate and cleft lip resulting in difficulty in feeding were excluded. Mothers of twins were excluded to eliminate recall bias. Children with health issues needing a special diet were also excluded. Data was analyzed by SPSS Version 23.

\section{RESULTS}

Our study includes 384 mothers, age range 19-41 years (mean 28 year, standard deviation 0.5 ) most of them $77.3 \%$ $(n=297) \quad$ were house wives while $22.7 \%(n=87)$ were working women. Data about education level and age is given in Table-I.

We observed that the awareness about the beneficial effects of colostrum, increased with increasing levels of maternal education. About $38 \%$ of mothers without formal education and $35 \%$ mothers with intermediate qualification were unaware about its benefits while on the other hand only $24 \%$ of mothers with higher education were assessed and found unaware of the same $(\mathrm{p}=0.05)$. The level of awareness about colostrum also increased with age $34.5 \%$ of young mothers of less than 30 years were unaware about the benefits of colostrum while only $25.5 \%$ of mature mothers were unfamiliar.

Although the feeding practice of colostrum increased with increasing level of education among mothers: $71 \%, 74 \%$ and $86 \%$ of mothers without formal education, intermediate and higher qualification respectively, a significant number of mothers were observed not giving colostrum to their babies. 
Table-I: Demographic data of study population

\begin{tabular}{ccc}
\hline & Demographics & \\
\hline $\begin{array}{c}\text { Maternal } \\
\text { Education }\end{array}$ & & $\mathrm{n}(\%)$ \\
& Unschooled & $68(17.40)$ \\
& Intermediate & $179(46.80)$ \\
& Higher Education & $130(33.90)$ \\
& Missing Information & $7(1.90)$ \\
\hline Maternal Age & Total & $384(100.00)$ \\
& $<30$ years & $232(60.90)$ \\
& $>30$ years & $152(39.10)$ \\
\hline Location & Total & $384(100.00)$ \\
& Rural & $19(4.80)$ \\
\hline Monthly & Urban & $143(37.00)$ \\
Income & Peri-Urban & $222(58.20)$ \\
& $\leq 20,000$ Rs. & $112(30)$ \\
& Up to 50,000 Rs. & $194(50)$ \\
& $\geq 100,000$ & $78(20)$ \\
\hline
\end{tabular}

Table-II: Reasons for not giving Colostrum.

\begin{tabular}{ccccccc}
\hline & & $\begin{array}{c}\text { Elder's Advise } \\
\mathbf{n}(\%)\end{array}$ & $\begin{array}{c}\text { perception that } \\
\text { it is not clean } \\
\mathbf{n}(\%)\end{array}$ & $\begin{array}{c}\text { Baby was in nursery } \\
\mathbf{n}(\%)\end{array}$ & $\begin{array}{c}\text { Baby did not take } \\
\text { it n(\%) }\end{array}$ & $\begin{array}{c}\text { Mother had } \\
\text { C-Section n(\%) }\end{array}$ \\
\hline \multirow{2}{*}{ Education } & Unschooled & $3(15.80)$ & $8(42.10)$ & $2(10.50)$ & $5(26.30)$ & $1(5.30)$ \\
Age & Intermediate & $15(32.60)$ & $9(19.60)$ & $2(4.30)$ & $15(32.60)$ & $5(10.90)$ \\
& Higher Education & $6(28.50)$ & $2(9.50)$ & $1(4.80)$ & $1(1.10)$ & $8(38.10)$ \\
& $<30$ years & $16(28.60)$ & $12(21.40)$ & $1(1.80)$ & $20(35.70)$ & $7(12.50)$ \\
\hline
\end{tabular}

The reasons for not giving colostrum are listed in TableII below; A decline in the proportion of mothers whose perceived that colostrum is not clean was noted from $42 \%$ to $20 \%$ to $9.5 \%$ as their education level improved from being untaught to highly educated. It is interesting to note that $38 \%$ of highly qualified mums held c-section accountable, in contrast to only $5.3 \%$ and $11 \%$ mothers belonging to unschooled and intermediate education groups as the reason for not feeding colostrum. On comparing the responses of younger mothers ( $<30$ years) with older ones (more than 30 years), $36 \%$ stated baby's refusal in feeding colostrum while $26 \%$ (each) of mature mums mentioned family's elders' discouragement and having a $\mathrm{C}$-section as the reason for not giving colostrum to baby.

Mothers belonging to each of the 3 educational groups breast fed their child 83.2\% (149) in the unschooled, $83.2 \%$ (149)

Table-III: Use of supplemental feed.

\begin{tabular}{ccccc}
\hline & Category & Yes & No & p-value \\
\hline \multirow{2}{*}{ Education } & Intermediate & $108(60)$ & $71(40)$ & \\
& Unschooled & $48(70)$ & $20(30)$ & $<0.001$ \\
& $\begin{array}{c}\text { Higher } \\
\text { Education }\end{array}$ & $103(79)$ & $27(21)$ & \\
& $<30$ years & $155(67)$ & $77(33)$ & 0.30 \\
\hline
\end{tabular}

Figure-I: Reasons for the addition of supplemental feed.

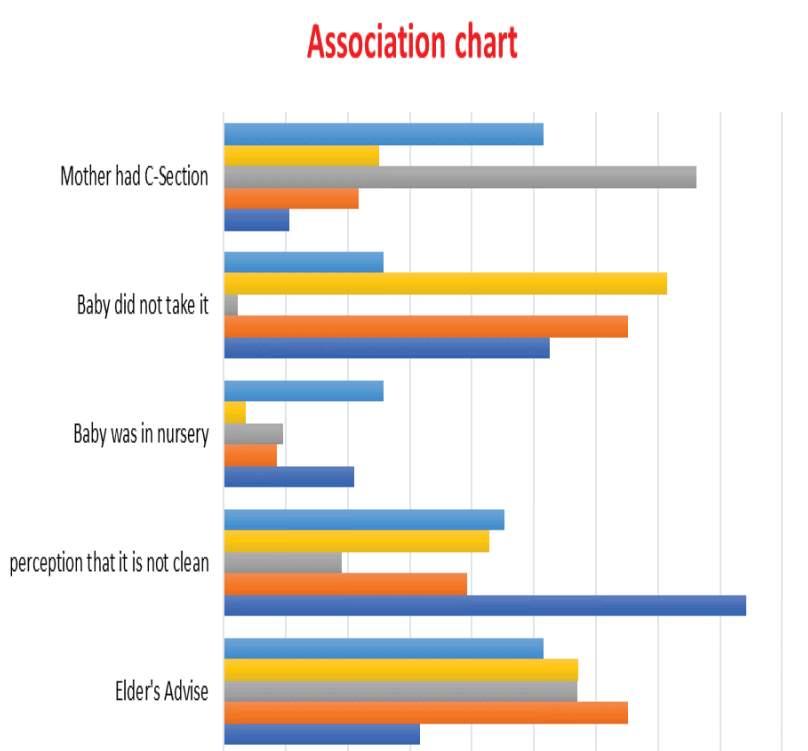

$0.00 \% \quad 5.00 \% \quad 10.00 \% \quad 15.00 \% \quad 20.00 \% \quad 25.00 \% 30.00 \% \quad 35.00 \% \quad 40.00 \% \quad 45.00 \%$

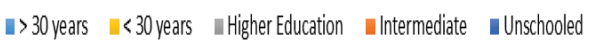

in intermediate pass and 90\% (117) in the highly educated mother category however, we observed that a notable number of mothers added supplemental feed. The results are shown below in table-III.

Regardless of the educational status and their age, the leading reason given by mothers to supplemental feed was they believed they were not producing enough breast milk to adequately feed their child. Various reasons given by mothers of adding supplemental feed are illustrated in Figure-I.

Mothers from different educational backgrounds level made different choices for supplemental feed 59.6\% $(n=31)$ of unschooled mothers chose bovine milk while $79.4 \%(n=81)$ of highly educated mothers chose formula milk as top feed $(\mathrm{p}=0.000)$.

Another important factor on which the choice of additional feed was dependent was the household's monthly income. Families with monthly income less than rupees (Pakistani) twenty thousand per month, 50\% were giving cow's milk and $100 \%$ of them were diluting it before feeding to their child. Only $37.5 \%$ of them used formula milk. Families with higher income i.e., Rs. 100,000 per month, 91.4\% gave formula milk $(\mathrm{p}=0.00)$.

On inquiring whether mothers were aware that use of cow`s/ buffalo milk before the age of 1 year can lead to iron deficiency anemia, we identified that this information 
was lacking in overwhelming majority $(80 \%)$ of mothers irrespective of education and age, they did not know about it as depicted in figure-II.

Figure-II: Awareness that bovine milk causes anemia before the age of 1 year.

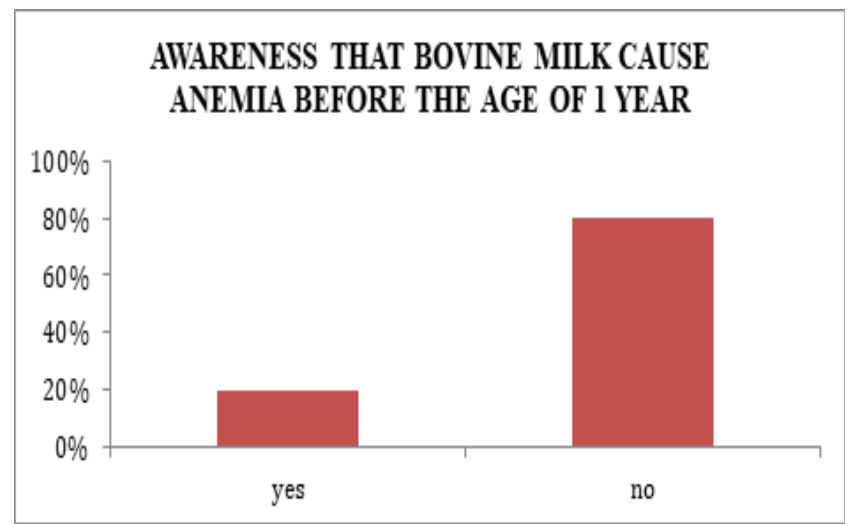

\section{DISCUSSION}

The responsibility of infant's upbringing and making the right food choices predominantly lies with the mother. It is important that their knowledge regarding nutrition and feeding practices is upgraded and according to the infant feeding guidelines. Maternal knowledge is highly influenced by culturally accepted norms, reinforced from elders and peers rather than sound knowledge based on breast milk nutritional value. This study particularly focused on colostrum feeding, breast feeding practices and addition of any supplemental feed before one year of age. To the best of our knowledge, this is the first study in which in addition to KAP regarding colostrum, breastfeeding, supplemental feeding, knowledge about anemia caused by the use of cow's milk, was also assessed.

This study highlighted that family's elders' misconceptions about colostrum and mothers' own perception that breast milk is not enough for the baby were top most reasons that effects babies feeding practice. The study in Induri, Thailand engaged grandmothers in an experimental learning with empowerment strategies and social support program (ELESSS). Grandmothers attend 2 days of ELESSS program and also refresher course at two and four months after deliver. In the refresher course they reinforce the importance of breastfeeding and discuss the barriers they observe in breastfeeding. There was a significant improvement noted in breastfeeding practice in intervention group ${ }^{[15]}$. While doing this study, we observed that local untrained Dai`s (traditional birth attendant) and elders also have a significant influence on mothers and encouraged practices to discard colostrum It was also noted that a significant number of young mothers $(10 \%)$ gave the reason that baby don't take it and this may be related to their inadequate knowledge about lactation techniques. Another study done in Ethopia also highlight that ineffective breastfeeding technique among primigradiva was the cause of inadequate breast feeding ${ }^{[22]}$.
One of the ways to deal with the maternal perception that breast milk was inadequate is reassurance, counseling, and identification of clinical signs of sufficient milk (steady growth, infant alertness, sufficient elimination, breast full before and soft after feeding) so they can have confidence that milk enough and only add supplemental feed in case of clinically correlated insufficient milk supply ${ }^{[23]}$.

One of the mean to deal with to the paucity of knowledge regarding development of anemia due to use of bovine milk in infants, can be addressed during antenatal visits where either a nutritionist or primary care physician can provide verbal and written information about it.

RECOMMENDATIONS: It is concluded from the study that there is a need to educate about the importance of breast feeding, especially benefits of colostrum not only to the mothers but also other people who are involved in giving feeding advice to mothers like traditional birth attendants and familys' grandparents. There should be lactation consultants for proper guidance of the mothers. Mothers having a perception of inadequate breast milk should be counseled about the clinical signs of inadequate breast milk in primary health care/postnatal centers. Information about the benefits of colostrum and exclusive breast feeding on media rather than promotion of breast milk substitutes would certainly help primary care providers deal with the current knowledge gap.

ACKNOWLEDGEMENT: None. CONFLICT OF INTEREST: None.

GRANT SUPPORT AND FINANCIAL DISCLOSURE: None.

\section{REFERENCES}

1. Bryant J, Thistle J. Anatomy, Colostrum. [Updated 2020 Nov 2]. In: StatPearls [Internet]. Treasure Island (FL): StatPearls Publishing; 2021 Jan-. Available from: https://www.ncbi.nlm.nih.gov/books/NBK513256/

2. Sarah lawson. Studycom/academy/lesson/whatis-colostrum-definition-benefits-side-effectshtml. [Online]. Available from: https://study.com/academy/ lesson/what-is-colostrum-definition-benefits-sideeffects.html [Accessed 11 November 2021].

3. Mehmood H, Khan Z, Rauf A, Waqar A. Breastfeeding temporal distribution trends among neonates in tertiary care hospital in lahore. Journal of University Medical \& Dental College. 2021;12(2):126-132.

4. Mose A, Dheresa M, Mengistie B, Wassihun B, Abebe H. Colostrum avoidance practice and associated factors among mothers of children aged less than six months in Bure District, Amhara Region, North West, Ethiopia: A community-based cross-sectional study. PloS one. 2021;16(1):e0245233.

5. Memon J, Holakouie-Naieni $\mathrm{K}$, Majdzadeh $\mathrm{R}$, Yekaninejad MS, Garmaroudi G, Raza O, et al. Knowledge, attitude, and practice among mothers about newborn care in Sindh, Pakistan. BMC Pregnancy and Childbirth. 2019;19(1):1-9. 
6. Lis-Kuberka J, Orczyk-Pawiłowicz M. Sialylated oligosaccharides and glycoconjugates of human milk. The impact on infant and newborn protection, development and well-being. Nutrients. 2019;11(2):306. Doi: 10.3390/nu11020306

7. Cando RI, DíazSilva A, Guerendiain M. The cognitive performance of indigenous schoolchildren in relation to their feeding during infancy. American Journal of Human Biology. 2020;32(2):e23326. Doi: 10.1002/ ajhb. 23326

8. Deoni S, Dean III D, Joelson S, O'Regan J, Schneider N. Early nutrition influences developmental myelination and cognition in infants and young children. Neuroimage. 2018;178:649-659. Doi:10.1016/j.neuroimage

9. Maryam yunus. World health organization. [Online]. Available from: http://www.emro.who.int/pak/pakistannews/breastfeeding-gives-babies-the-best-possiblestart-in-life-and-breastmilk-works-like-a-babys-firstvaccine.html [Accessed 8 November 2021].

10. World health organization. www.who.int. [Online]. Available from: https:/www.who.int/news-room/factsheets/detail/infant-and-young-child-feeding [Accessed 9 November 2021].

11. Zakar R, Zakar MZ, Zaheer L, Fischer F. Exploring parental perceptions and knowledge regarding breastfeeding practices in Rajanpur, Punjab Province, Pakistan. International breastfeeding journal. 2018;13(1):1-2.

12. Kaplan DL, Graff KM. Marketing breastfeeding reversing corporate influence on infant feeding practices. Journal of Urban Health. 2008;85(4):486504. Doi:10.1007/s11524-008-9279

13. Khan MA, Qureshi Z, Khan KA, Gill FN. Patterns and determinants of breast feeding among mother infant pairs in Dera ghazi khan, Pakistan. Journal of Ayub Medical College Abbottabad. 2016;28(4):750-754.

14. Cascone D, Tomassoni D, Napolitano F, Di Giuseppe G. Evaluation of knowledge, attitudes, and practices about exclusive breastfeeding among women in Italy. International journal of environmental research and Public Health. 2019;16(12):2118. Doi: 10.3390/ ijerph16122118

15. Ikram A, Sajid A. Evaluation of Breastfeeding Practices in The Community Attending a Tertiary Care Hospital. Journal of University Medical \& Dental College. 2010;1(1):14-8.

16. Zakar R, Zakar MZ, Zaheer L, Fischer F. Exploring parental perceptions and knowledge regarding breastfeeding practices in Rajanpur, Punjab Province, Pakistan. International breastfeeding Journal. 2018;13(1):1-2.

17. Karmacharya C, Cunningham K, Choufani J, Kadiyala S. Grandmothers' knowledge positively influences maternal knowledge and infant and young child feeding practices. Public Health Nutrition. 2017;20(12):21142123.
18. Anthony Porto, MD, MPH, FAAP, Rachel Drake, MS, et al. Cow's Milk Alternatives. 2017 Oct 13 [Cited 2021 feb 02). Available from: https://www.healthychildren. org/English/healthy-living/nutrition/Pages/milkallergy-foods-and-ingredients-to-avoid.

19. Ziegler EE. Consumption of cow's milk as a cause of iron deficiency in infants and toddlers. Nutrition Reviews. 2011 Nov 1;69(suppl_1):S37-42.

20. Kellams A, Harrel C, Omage S, Gregory C, RosenCarole C. Academy of Breastfeeding Medicine. ABM clinical protocol\# 3: supplementary feedings in the healthy term breastfed neonate, revised 2017. Breastfeeding Medicine. 2017;12(4):188-198. Doi:10.1089/bfm.2017.29038.ajk

21. Microsoft Corporation. Geography, Human Geography, Social Studies, U.S. History, World History.[ cited 2021 Nov 02]. Available from: https://www. nationalgeographic.org/encyclopedia/urban-area/.

22. Yilak G, Gebretsadik W, Tadesse H, Debalkie M, Bante A. Prevalence of ineffective breastfeeding technique and associated factors among lactating mothers attending public health facilities of South Ari district, Southern Ethiopia. PloS one. 2020;15(2):e0228863.

23. Español. Warning Signs of Breastfeeding Problems. https://www.healthychildren.org/English/agesstages/baby/breastfeeding/Pages/Warning-Signs-ofBreastfeeding-Problems.aspx. [Cited $2021 \mathrm{feb} 26$ ].

\section{Authors Contribution:}

Hina Jawaid: Involved in designing the project. Developing survey questionnaire drafting article critical revision along with final approval of revision to be published.

Marriam Sheraz: Involved in the designing of project questionnaire, piloting it, collecting data, literature review, interpretation of results, article writeup as a main author.

Khudija Amna Arif: Developing questionnaire, piloting it, collecting it, interpretation of results and writeup.

Zia Ul Hasan: Contributed in generating the basic theme of research title designing the project and critical review at different steps of research.

Hina Akhter: Assisted in data collection and facilitated throughout the research process at all steps.

Submitted for publication: 23-08-2021

Accepted after revision: 04-01-2022 